\title{
Recovery of pulmonary structure and exercise capacity by treatment with granulocyte-colony stimulating factor (G-CSF) in a mouse model of emphysema
}

\author{
Gustavo Fortunato $^{\text {a }}$, Daniel T.A. Vidal ${ }^{\text {b,c }}$, Wilfried Klein ${ }^{\text {d,e }}$, Alberto Neto ${ }^{\text {a,c }}$, \\ André Angrizani ${ }^{\mathrm{b}}$, Juliana F. Vasconcelos ${ }^{\mathrm{a}, \mathrm{b}}$, Carla Kaneto ${ }^{\mathrm{c}}$, \\ Bruno Solano de Freitas Souza ${ }^{c}$, Ricardo Ribeiro-dos-Santos ${ }^{c}$, Milena B.P. Soares ${ }^{\text {a,b,c }}$, \\ Simone G. Macambira ${ }^{a, b, c, f, *}$ \\ a Programa de Pós-Graduação em Biotecnologia, Universidade Estadual de Feira de Santana, Feira de Santana, BA, Brazil \\ ${ }^{\mathrm{b}}$ Centro de Pesquisas Gonçalo Moniz, Fundação Oswaldo Cruz, Salvador, BA, Brazil \\ ${ }^{c}$ Centro de Biotecnologia e Terapia Celular, Hospital São Rafael, Salvador, BA, Brazil \\ ${ }^{\mathrm{d}}$ Departamento de Biologia, Faculdade de Filosofia, Ciências e Letras de Ribeirão Preto, Universidade de São Paulo, SP, Brazil \\ e Instituto Nacional de Ciência e Tecnologia em Fisiologia Comparada, UNESP, Rio Claro, SP, Brazil \\ ${ }_{\mathrm{f}}$ Departamento de Biofunção, Instituto de Ciências da Saúde, Universidade Federal da Bahia, BA, Brazil
}

\section{A R T I C L E I N F O}

\section{Article history:}

Received 3 November 2012

Received in revised form

1 April 2013

Accepted 2 April 2013

\section{Keywords:}

Pulmonary emphysema

G-CSF

Mean linear intercept

Exercise capacity

\begin{abstract}
A B S T R A C T
Emphysema is a chronic obstructive pulmonary disease characterized abnormal dilatation of alveolar spaces, which impairs alveolar gas exchange, compromising the physical capacity of a patient due to airflow limitations. Here we tested the effects of G-CSF administration in pulmonary tissue and exercise capacity in emphysematous mice. $\mathrm{C} 57 \mathrm{Bl} / 6$ female mice were treated with elastase intratracheally to induce emphysema. Their exercise capacities were evaluated in a treadmill. Lung histological sections were prepared to evaluate mean linear intercept measurement. Emphysematous mice were treated with G-CSF ( 3 cycles of $200 \mu \mathrm{g} / \mathrm{kg} /$ day for 5 consecutive days, with 7-day intervals) or saline and submitted to a third evaluation 8 weeks after treatment. Values of run distance and linear intercept measurement were expressed as mean $\pm \mathrm{SD}$ and compared applying a paired $t$-test. Effects of treatment on these parameters were analyzed applying a Repeated Measures ANOVA, followed by Tukey's post hoc analysis. $p<0.05$ was considered statistically significant. Twenty eight days later, animals ran significantly less in a treadmill compared to normal mice $(549.7 \pm 181.2 \mathrm{~m}$ and $821.7 \pm 131.3 \mathrm{~m}$, respectively; $p<0.01)$. Treatment with G-CSF significantly increased the exercise capacity of emphysematous mice $(719.6 \pm 200.5 \mathrm{~m})$, whereas saline treatment had no effect on distance run $(595.8 \pm 178.5 \mathrm{~m})$. The PCR cytokines genes analysis did not detect difference between experimental groups. Morphometric analyses in the lung showed that saline-treated mice had a mean linear intercept significantly higher $(p<0.01)$ when compared to mice treated with G-CSF, which did not significantly differ from that of normal mice. Treatment with G-CSF promoted the recovery of exercise capacity and regeneration of alveolar structural alterations in emphysematous mice.
\end{abstract}

(c) 2013 Elsevier Ltd. All rights reserved.
Abbreviations: G-CSF, granulocyte-colony stimulating factor; COPD, chronic obstructive pulmonary disease; Lm, mean linear intercept; ATRA, all-trans-retinoic acid.

* Corresponding author. Departamento de Biofunção, Universidade Federal da Bahia, Instituto de Ciências da Saúde, Av. Reitor Miguel Calmon, s/n. Vale do Canela, 40110-100 Salvador, BA, Brazil. Tel.: +55 71 32838918; fax: +55 7132838894 .

E-mail addresses: gustavofortunato@cirtoraxbahia.com.br (G. Fortunato), andion07@hotmail.com (D.T.A. Vidal), klein@ffclrp.usp.br (W. Klein), assbneto@ hotmail.com (A. Neto), anangrisani@hotmail.com (A. Angrizani), julianafvs@ gmail.com (J.F. Vasconcelos), carlakaneto@gmail.com (C. Kaneto), brunosolanosouza@gmail.com (B.S.deF. Souza), ricardo.ribeiro@hsr.com.br (R. Ribeiro-dos-Santos), milena@bahia.fiocruz.br (M.B.P. Soares), simone@ bahia.fiocruz.br (S.G. Macambira).

\section{Introduction}

Chronic obstructive pulmonary disease (COPD) is a slowly progressive respiratory disease due to an exacerbated inflammatory process in lungs triggered by exposure to noxious particles or gases, especially cigarette smoke [1]. Characterized by airflow limitation, COPD is not a fully reversible condition, and is one of the major causes of chronic disability and permanent impairment. The prevalence of COPD will increase in the coming years to become the fifth most common cause of morbidity and the third most common 
chronic disease worldwide [2]. According to new estimates for 2030 , COPD is predicted to become the third leading cause of death [3].

Belonging to the group of COPD, emphysema is characterized by destruction of alveolar extracellular matrix, leading to airspace enlargement of the distal airspaces and a reduction in the alveolar capillary exchange area. These results in a largely irreversible airflow obstruction, usually progressive, associated with an abnormal inflammatory response of the lungs [1]. Pulmonary emphysema is notoriously unresponsive to medical treatment and no currently available pharmacological intervention has been shown to slow or halt the progression of the disease. Therefore, lung transplantation remains the only definitive therapeutic option for patients with advanced emphysema [4].

Granulocyte colony-stimulating factor (G-CSF) is a $20-\mathrm{kDa}$ glycoprotein known to induce granulopoiesis. Since it acts as a critical regulator of myeloid progenitor cell proliferation, differentiation and survival, the G-CSF is currently used therapeutically for the treatment of leukopenia associated to chemotherapy [5]. More recently, different and interesting pleiotropic actions of G-CSF were reported, such as restoration of cardiac function and tissue repair both in ischemic heart disease [6-8] and in chronic chagasic cardiomyopathy [9], as well as in lung tissue $[10,11]$.

Based on the data described in the literature about the potential therapeutic use of G-CSF, in the present study we aimed to investigate the therapeutic potential of G-CSF in emphysematous lung. Using an experimental model for emphysema developed in C57Bl/6 mice by intratracheal administration of porcine pancreatic elastase [12], we tested the effects of G-CSF in tissue repair of the lungs and functional recovery of the animals.

\section{Material and methods}

\subsection{Animals}

Two-month-old female C57BL/6 mice, raised and maintained in the animal facilities at the Gonçalo Moniz Research Center, Oswaldo Cruz Foundation (Salvador, Bahia, Brazil) were used in the experiments, and were provided with rodent diet and water ad libitum. All animals were sacrificed in a $\mathrm{CO}_{2}$ chamber, and handled according the National Institutes of Health guidelines for ethical use of laboratory animals. This study was approved by Ethics Committee of Animal Use of Gonçalo Moniz Research Center.

\subsection{Emphysema induction}

C57Bl/6 female mice $(n=30)$ were anesthetized via inhalation of isofluorane (0.5-2\%). The anesthetic concentration offered was controlled by monitoring the heart rate, which was kept above $350 \mathrm{bpm}$. Anesthetized, the animals were placed in a supine position on a heated table to be submitted to instillation of $100 \mu \mathrm{l}$ of elastase (2 U/100 g body weight porcine pancreatic elastase; Sigma, Aldrich, Taufkirchen, Germany) dissolved in saline $(n=20)$ by intratracheal route. Normal control animals were not manipulated $(n=10)$. The animals were submitted to anterior cervical incision and the muscle were divulsed in order to visualize the trachea and make the tracheal punction to administer the solutions. Afterwards, mice were sutured, kept on a warm plate $\left(30^{\circ} \mathrm{C}\right)$ until restoration of spontaneous breathing, after which they were extubated.

\subsection{Treatment with G-CSF}

Twenty-eight days following elastase-induced emphysema, the physical capacity of the animals was reevaluated during 5 consecutive days (treadmill challenge). After this, emphysematous mice were separated in two experimental groups, using the following treatment protocol. The G-CSF treated group $(n=10)$ received human recombinant G-CSF $(200 \mu \mathrm{g} / \mathrm{kg} / \mathrm{d}$; Granulokine 30; Hoffman la Roche, Switzerland) via intraperitoneal route. This treatment was performed in 3 cycles, where each cycle lasted 5 consecutive days, with a 7 day interval between each cycle. The second group of emphysematous mice $(n=10)$ was submitted to the same treatment protocol, receiving saline, as opposed to G-CSF.

\subsection{Treadmill}

A motor-driven treadmill chamber for one animal (LE 8700 Panlab, Barcelona, Spain) was used to exercise the animals. The speed of the treadmill and the intensity in milliamps of the shock were controlled by a potentiometer (LE 8700 treadmill control, Panlab). Room air was pumped into the chamber at a controlled flow rate $(600 \mathrm{ml} / \mathrm{min}$ ) by a chamber air supplier (OXYLET LE 400 , Panlab). The mean room temperature was maintained at $21 \pm 1{ }^{\circ} \mathrm{C}$. After an adaptation period of $40 \mathrm{~min}$ in the treadmill chamber the mice were exercised at different velocities, starting at $7.2 \mathrm{~m} / \mathrm{min}$ and increasing the velocity $7.2 \mathrm{~m} / \mathrm{min}$ every $10 \mathrm{~min}$. The inclination of the treadmill was maintained at an uphill angle of $10^{\circ}$. Velocities were increased until the animal could no longer sustain a given speed and remained for more than $10 \mathrm{~s}$ on an electrified stainless steel grid, which provided an electrical stimulus ( 1 milliamp) to keep the mice running. Total running distance and running time were recorded. Treadmill tests were carried out on all mice prior to emphysema induction. The initial reevaluation of these mice took place 28 days after intratracheal administration of elastase/saline, and again 8 weeks after the conclusion of the administered treatment protocol.

\subsection{Histological and morphometrical analysis}

Mice were sacrificed 8 weeks after the end of the treatment, using $\mathrm{CO}_{2}$. Opening the thorax and abdomen, the lungs were exposed. The trachea was cannulated with gelco number 18 and the lungs were perfused with buffered $4 \%$ formalin applying a constant transpulmonary pressure of $20 \mathrm{~cm} \mathrm{H}_{2} \mathrm{O}$ for $2 \mathrm{~h}$. After this procedure the trachea was sutured in order to hold the intrapulmonary pressure at $20 \mathrm{~cm} \mathrm{H}_{2} \mathrm{O}$ and the entire cardiopulmonary tissue block was removed and fixed in formalin (4\%). Lung histological sections were prepared to evaluate mean linear intercept (Lm). Analyses were performed on whole lung sections after slide scanning with $20 \times$ magnification using the Aperio ScanScope system (Aperio Technologies, Vista, CA). Morphologic examinations were performed following Thurbeck [13]. The Lm of each lung was determined using light microscopy on 20 randomly selected fields, originating from randomly selected tissue samples covering the entire lung and containing apical as well as basal areas of the organ using ImageScope software (Aperio Technologies). The Lm, as indicator of air space size, was calculated from counting lines of defined length that were randomly placed on each of the 20 lung sections of $5 \mu \mathrm{m}$-thick and the number of intercepts crossing the lines counted. The $\mathrm{Lm}$ was calculated from the length of the lines multiplied by the number of the lines divided by the sum of all counted intercepts.

\subsection{Sample preparation - RNA isolation and cDNA synthesis}

Immediately following the mice sacrifice, RNA was harvested from lung tissue, isolated with TRIzol reagent (Invitrogen) and the concentration was determined photometricly. The RNA quality was analyzed in $1.2 \%$ agarose gel. A High Capacity cDNA Reverse 
Transcription Kit (Applied Biosystems) was used to synthesize cDNA of $2 \mu \mathrm{g}$ RNA following the manufacturer's recommendations.

\section{7. $q R T-P C R$ analysis}

Real-time RT-PCR assays were performed to detect the expression levels of IL6 (Mm 00446190_m1); HGF (Mm 01135193_m1); VEGF (Mm 00437304_m1); MMP9 (Mm 00442991_m1); Endothelin (Mm 00438656_m1); TIMP (Mm00441818_m1); TGF- $\beta$ (Mm 00441724_m1); ADM (Mm 00437438_g1); Chi3L3 (Mm 00657889_mH); $\quad$ MRC1(Mm 00485148_m1); Tinagl (Mm 00469812_m1) and NOS2 (Mm 01309898_m1). qRT-PCR amplification mixtures were made with Universal Master Mix (Applied Biosystems) and 7500 Real Time PCR System (Applied Biosystems). The cycling conditions comprised 10 min polymerase activation at $95{ }^{\circ} \mathrm{C}$ and 40 cycles at $95^{\circ} \mathrm{C}$ for $15 \mathrm{~s}$ and $60{ }^{\circ} \mathrm{C}$ for $60 \mathrm{~s}$

\subsection{Statistical analysis}

Numeric values were expressed as mean \pm SD and compared applying a paired $t$-test. Effects of each treatment on run distance and mean linear intercept measurement were analyzed applying a Repeated Measures ANOVA, followed by Tukey's post hoc analysis, using Prism 5.0 software. A value of $p<0.05$ was considered statistically significant. Data obtained from Real-time RT-PCR assays were analyzed by Bartlett's test for equal variances, followed by one-way ANOVA and Tukey's post hoc analysis.

\section{Results}

3.1. G-CSF treatment eversed the low capacity to exercise induced by elastase intratracheal administration

In order to investigate the therapeutic potential of G-CSF on emphysema, all experimental groups of mice were submitted to ergometry test on treadmill to evaluate their exercise capacity. Mice which received elastase by intratracheal route reduced their exercise capacity significantly. Emphysematous mice treated with saline maintained this reduction 8 weeks after the treatment. In contrast, G-CSF-treated emphysematous mice recovered their exercise capacity, running significantly longer distances when compared to the exercise performance recorded 28 days after emphysema induction. Normal mice did not have their ability to perform physical exercise altered throughout the study (Fig. 1).

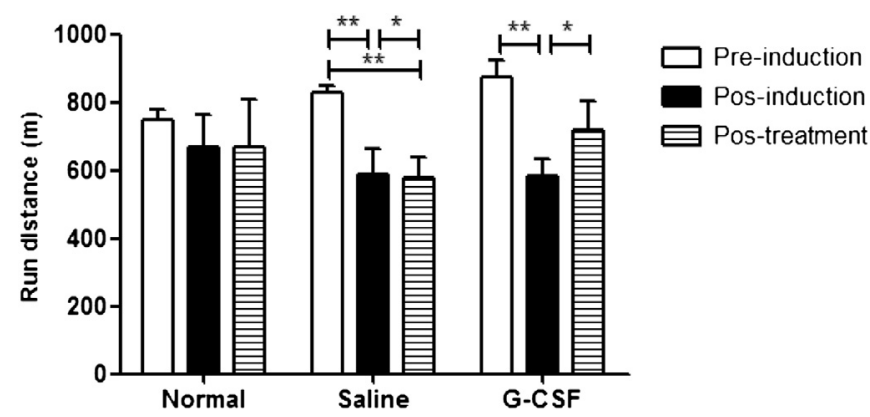

Fig. 1. GCS-F recovered the exercise capacity in emphysematous mice. Running distance measurements in normal $(n=10)$ and emphysematosus $(n=10)$ mice before emphysema induction (Pre-induction); 28 days after emphysema induction (Post-induction) and 8 weeks after treatment (Post-treatment). Repeated Measures ANOVA, followed by Tukey's post hoc analysis, using Prism 5.0 software. ${ }^{* *} p<0.01,{ }^{*} p<0.05$.
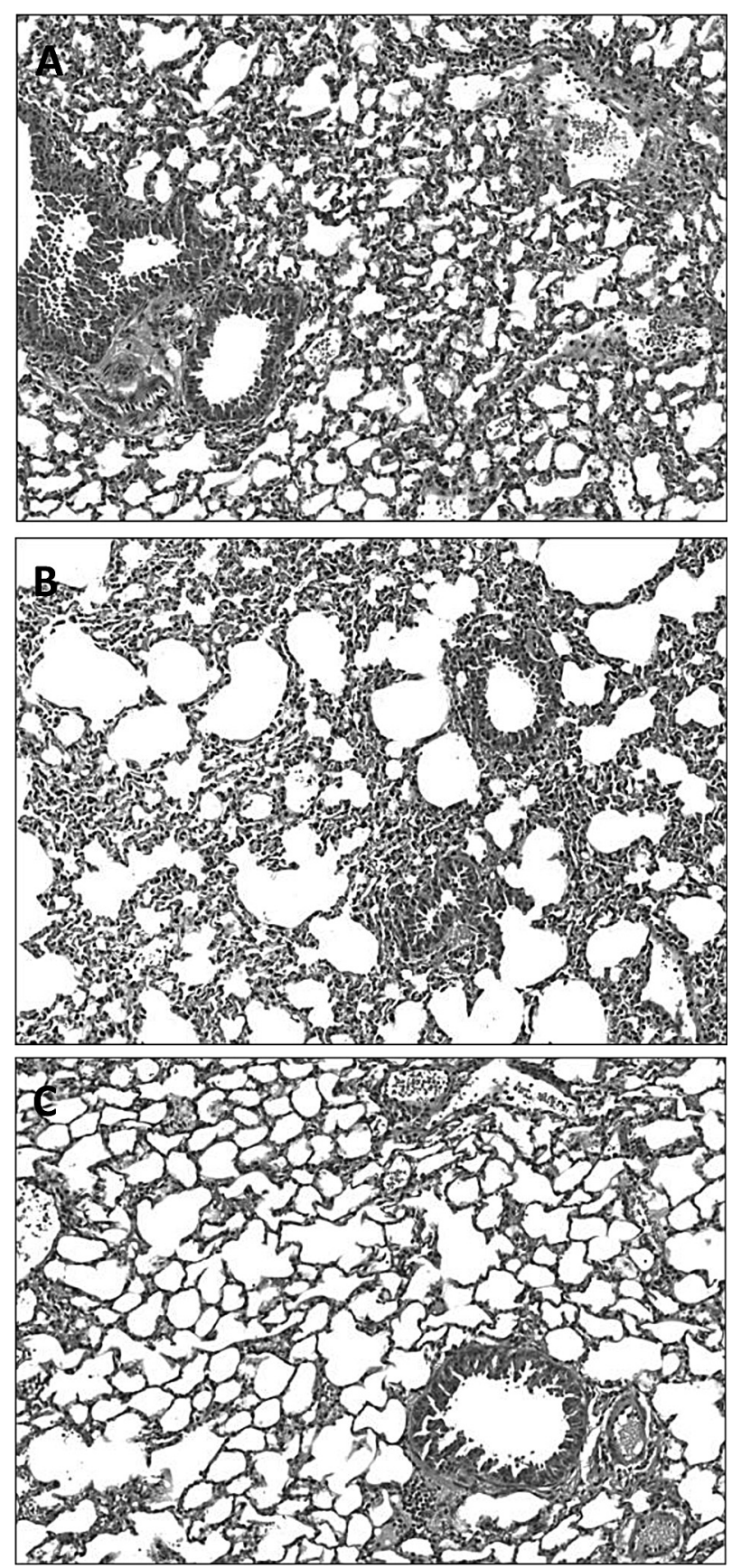

Fig. 2. G-CSF repaired alveolar structural in emphysematous mice. Representative histological sections of lung tissue from normal mouse (A), saline-treated emphysematous mouse (B) and G-CSF-treated emphysematous mouse (C). Normal and G-CSF treated emphysematous mice showed alveolar walls and blood vessels intact. Saline treated emphysematous mouse showed large areas of alveolar destruction.

\subsection{Reconstruction of alveolar structure after G-CSF treatment}

Comparing the histological pulmonary sections obtained from emphysematous mice treated with G-CSF (Fig. 2C) to the one treated with saline (Fig. 2B), it was shown that G-CSF treatment was capable of restoring pulmonary parenchyma, as could be observed by the integrity of alveolar septum similar to observed in normal control mice (Fig. 2A).

The Lm of G-CSF-treated emphysematous mice was not statically different to the ones obtained from non-manipulated mice 


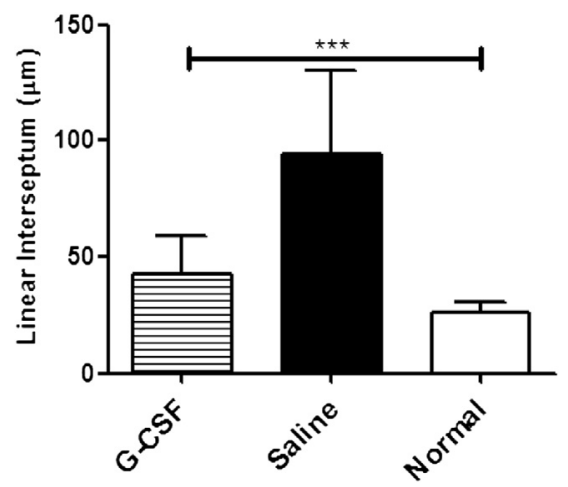

Fig. 3. G-CSF reduced the mean linear intercept in emphysematous mice. Comparison of the mean linear intercept length in normal mice $(n=10)$, emphysematosus mice treated with saline $(n=9)$ and G-CSF $(n=9)$. Data are presented as mean \pm S.E.M. ${ }^{* * *} p<0.01$.

(Fig. 3). In contrast, the degeneration in emphysema induced by administration of elastase was not reversed in emphysematous mice treated with saline, showing significantly greater Lm when compared to normal or to G-CSF-treated mice (Fig. 3).

\subsection{Genes expression of cytokines and growth factors were not altered by G-CSF administration}

We evaluated the gene expression of IL6, HGF, VEGF, MMP9, Endothelin, TIMP, TGF- $\beta$, ADM, Chi3L3, MRC1, Tingal and NOS2. Among the cytokines and growth factors evaluated in this study, only genes expression of endothelin and MRC1 were reduced after emphysema induction by elastase (Fig. 4). However, the treatment with G-CSF did not affect gene expression of any cytokine or growth factor evaluated (Fig. 4).

\section{Discussion}

Many studies investigating different therapies to restore tissue function and to repair its structure have been developed during the last years. Bone marrow stem cells [14], mesenchimal stem cells [15] and growth factors such as G-CSF [16], GM-CSF [17], VEGF [18] and HGF [19] have been employed in experimental models of diverse chronic diseases, such as chronic chagasic cardiomyopathy, autoimmune encephalomyelitis, isquemic cardiomyopathy, neurological disease, renal chronic disease and pulmonary disease, as well in clinical studies [20].

In this study we demonstrated, for the first time, using functional and morphometric analyses, that G-CSF treatment induced recovery of the exercise capacity and alveolar structure in emphysematous mice. The pathophysiological mechanisms of physical incapacity related to emphysema are complex and include structural and functional disturbances such as weakness of respiratory muscle, gas exchange reduction and abnormalities in lung mechanics, reflecting in exercise intolerance. As previously demonstrated in the experimental model, emphysema compromises the ability to perform physical activity $[12,21]$. In this study, the respiratory function improvement was reflected by a greater exercise performance of emphysematous G-CSF-treated mice compared to saline-treated emphysematous mice. The mean linear intercept measurement showed that alveolar septa were significantly restored in G-CSF-treated mice. These effects could be due to many already described actions of G-CSF, such as mobilization of bone marrow-derived cells and resident tissue stem cells, repair of damaged tissue, induction of angiogenesis [22], reduction of inflammation and fibrosis [9,23], induction of apoptosis of inflammatory cells [9], and increase in connexin 43 expression [24].

In order to elucidate the possible mechanisms involved in these effects, we used PCR analysis to evaluate whether G-CSF was modulating the gene expression of cytokines and enzymes. However, no differences were observed in the genes investigated after elastase instillation or G-CSF treatment. Perhaps the regulation mediated by the G-CSF is on the gene expression of cytokine receptors such as CXCR2 and CXCR3 that are claimed as therapeutic targets in COPD [25].

Despite the many controversial studies in the literature that aimed to promote lung tissue repair and regeneration in emphysema by the administration of different growth factors such as HGF, ATRA $[19,26,27]$ or GM-CSF $[28,29]$, some of these corroborate the findings presented here. In 2004, Ishizawa et al. [10] demonstrated that administration of all-trans-retinoic acid (ATRA) and mobilization of bone marrow derived cells by G-CSF was involved in lung regeneration. The authors evaluated the distribution of bone marrow stem cells in the lung and the measurement of mean linear intercept in an experimental model of elastase-induced pulmonary emphysema. Both ATRA and G-CSF induced beneficial reparative
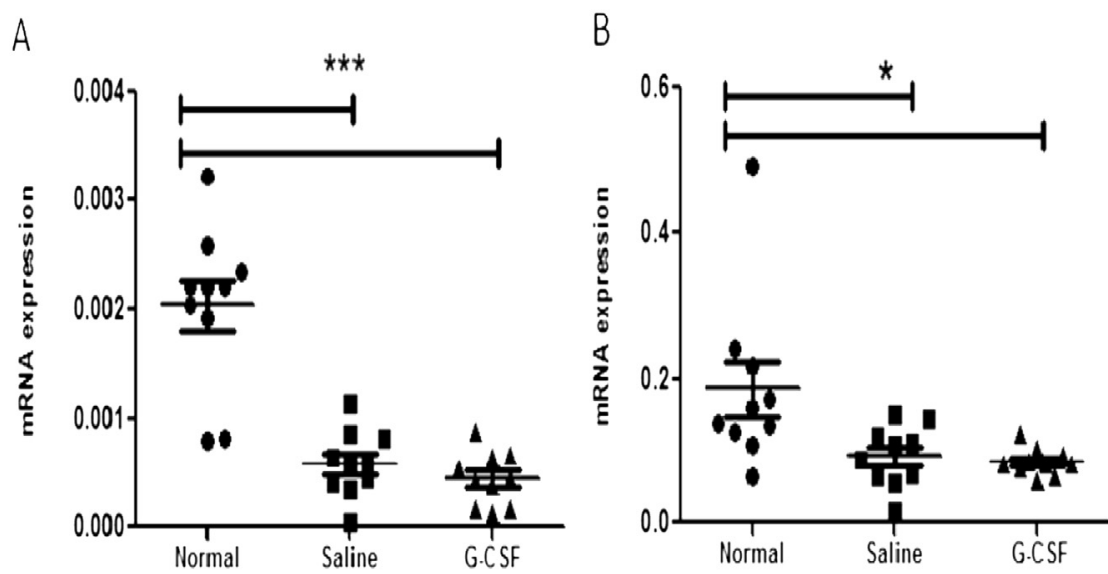

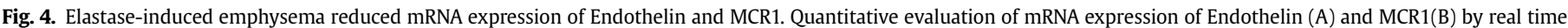

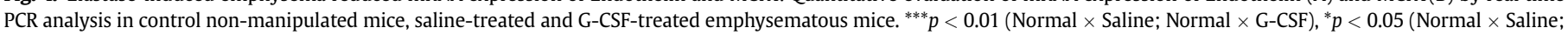
Normal $\times$ G-CSF). 
effects on lung structure and their association had an additive effect. However, Fujita et al. (2004) used the same experimental model developed in two different strains of mice to induce acute and chronic alveolar destruction, and reported that ATRA did not reverse emphysema, probably due to the increase of inflammatory process observed. Stinchcombe \& Maden (2008) showed that, although retinoic acid can induce alveolar regeneration in experimental emphysema, this effect is species and strain dependent. This fact could explain the positive effects described for retinoic acid treatment in emphysematous rats, first described by Massaro \& Massaro (1997).

Specifically concerning the effects of G-CSF, it was demonstrated that the protective effect of pre-elafin, an elastase inhibitor, on lungs of $\mathrm{C} 57 \mathrm{Bl} / 6$ mice submitted to porcine pancreatic elastase administration could be due in part to the increased local levels of $\mathrm{G}$-CSF, which in turn are associated with a reduction in the number of macrophages in broncoalveolar lavage, in the air space dimensions and in the lung hysteresivity [30]. The effects of the recombinant human G-CSF Nartograstim were evaluated in a model of emphysema developed in Sprague-Dawley rats. A beneficial action, namely the inhibition of Lm increase after elastase administration, was observed. However, G-CSF was only capable of reversing emphysematous lesions when the protocol administration of G-CSF was given to rats with well established emphysematous lesions [31]. Likewise, we reverted the functional disturbances and structural alterations 28 days after the administration of elastase when the emphysematous lesions were well developed.

We can assign in part the beneficial therapeutic effects described in our study to the ability of G-CSF to mobilize bone marrow stem cells. This hypothesis is supported by the findings described by Cruz et al. (2012) that pointed the protective effects of $2 \times 10^{6}$ bone marrow-derived mononuclear cells administrated $3 \mathrm{~h}$ after porcine pancreatic elastase instillation in female C57BL/6 mice [32]. Among these protective effects, the lower mean linear intercept and right ventricle wall thickness are noteworthy, being in accordance with the improvement in exercise capacity described in our study.

In the present study, we showed that structural repair led to a function recovery since the mice treated with G-CSF had the alveolar wall reconstitute and response to ergometry test in treadmill similar to that of normal mice. This indicates that alveolar gas exchange is reestablished through the recovery of pulmonary ventilation-perfusion relation.

The other fact that reinforces the use of G-CSF relates to the inflammatory responses developed by lungs against noxious particles, since many immunomodulatory effects are attributed to GCSF. There is a prominent inflammation during the development of emphysema that could be associated with exacerbated responses against toxic compounds that could lead to the apoptosis of pulmonary cells. If the efferocytosis fails to remove the dead cells, it could trigger an autoimmune process [33] that causes destruction of alveolar wall and some degree of fibrosis deposition due to a persistent inflammation [34-36]. G-CSF administration reduced apoptosis of cardiac myocytes and increased the apoptosis of inflammatory cells in damaged heart caused by T. cruzi infection [9]. Thus, a modulation of apoptosis may also occur in emphysematous lungs, leading to the restoration of the parenchyma and reestablishment of gas exchange, explaining the reversion of exercise intolerance observed in emphysematous mice.

Administration of G-CSF in experimental pulmonary emphysema had beneficial effects on lung structure, which were well correlated with improvements in exercise capacity. In this context, the administration of G-CSF emerges as a promising therapeutic option since emphysema is one of the leading causes of morbidity and mortality throughout the world and there are no treatment options to restore the functionality once the disease is diagnosed. So, due to the relevance of these findings, further studies are needed to investigate the mechanisms by which this growth factor has beneficial effects in emphysema.

\section{Conclusion}

This study showed for the first time by functional and structural analysis the therapeutic potential of G-CSF to treat experimental emphysema. G-CSF treatment induced alveolar regeneration in emphysematous mice, which was well correlated with the improved exercise capacity. These results suggest that the administration of GCSF may be a promising therapy for the treatment of chronic emphysematous patients with respiratory function committed.

\section{References}

[1] Pauwels RA, Buist AS, Calverley PM, Jenkins CR, Hurd SS. Global strategy for the diagnosis, management, and prevention of chronic obstructive pulmonary disease. NHLBI/WHO Global Initiative for Chronic Obstructive Lung Disease (GOLD) Workshop summary. Am J Respir Crit Care Med 2001;163:1256-76.

[2] Pauwels RA, Rabe KF. Burden and clinical features of chronic obstructive pulmonary disease (COPD). Lancet 2004;364:613-20.

[3] World Health Organization. Chronic respiratory diseases. COPD predicted to be third leading cause of death in 2030. World Health Statistics 2008.

[4] Cote CG, Celli BR. New treatment strategies for COPD. Pairing the new with the tried and true. Postgrad Med 2005;117:27-34

[5] Bottoni U, Trapasso F. The role of G-CSF in the treatment of advanced tumors. Cancer Biol Ther 2009;8:1744-6.

[6] Iwanaga K, Takano H, Ohtsuka M, Hasegawa H, Zou Y, Qin Y, et al. Effects of G CSF on cardiac remodeling after acute myocardial infarction in swine. Biochem Biophys Res Commun 2004;325:1353-9.

[7] Harada M, Qin Y, Takano H, Minamino T, Zou Y, Toko H, et al. G-CSF prevents cardiac remodeling after myocardial infarction by activating the Jak-Stat pathway in cardiomyocytes. Nat Med 2005;11:305-11.

[8] Fujita J, Mori M, Kawada H, Ieda Y, Tsuma M, Matsuzaki Y, et al. Administration of granulocyte colony-stimulating factor after myocardial infarction enhances the recruitment of hematopoietic stem cell-derived myofibroblasts and contributes to cardiac repair. Stem Cells 2007;25:2750-9.

[9] Macambira SG, Vasconcelos JF, Costa CRS, Klein W, Lima RS, Guimarães P, et al Granulocyte colony-stimulating factor treatment in chronic Chagas disease: preservation and improvement of cardiac structure and function. FASEB 2009;23:3843-50.

[10] Ishizawa K, Kubo H, Yamada M, Kobayashi S, Numasaki M, Ueda S, et al. Bone marrow-derived cells contribute to lung regeneration after elastase-induced pulmonary emphysema. FEBS Lett 2004;556:249-52.

[11] Azoulay E, Herigaut S, Levame M, Brocard L, Schlemmer B, Harf A, et al. Effect of granulocyte colony-stimulating factor on bleomycin-induced acute lung injury and pulmonary fibrosis. Crit Care Med 2003;31:1442-8.

[12] Vidal DTA, Fortunato GA, Klein W, Cortizo L, Vasconcelos JF, Ribeiro-dosSantos R, et al. Alterations in pulmonary structure by elastase administration in a model of emphysema in mice is associated with functional disturbances. Rev Port Pneumol 2012;18:128-36.

[13] Thurlbeck WM. Measurement of pulmonary emphysema. Am Rev Respir Dis 1967;65:752-64.

[14] Soares MB, Lima RS, Rocha LL, Takyia CM, Pontes-de-Carvalho L, Campos de Carvalho AC, et al. Transplanted bone marrow cells repair heart tissue and reduced myocarditis in chronic chagasic mice. Am J Pathol 2004;164:441-7.

[15] Constantin G, Marconi S, Rossi B, Angiari S, Calderan L, Anghileri E, et al. Adipose-derived mesenchymal stem cells ameliorate chronic experimental autoimmune encephalomyelitis. Stem Cells 2009;27:2624-35.

[16] Kuwabara M, Kakinuma Y, Katare RG, Ando M, Yamasaki F, Doi Y, et al Granulocyte colony-stimulating factor activates Wnt signal to sustain gap junction function through recruitment of $\beta$-catenin and cadherin. FEBS Lett 2007;581:4821-30.

[17] Hercus TR, Thomas D, Guthridge MA, Ekert PG, King-Scott J, Parker MW, et al. The granulocyte-macrophage colony-stimulating factor receptor: linking its structure to cell signaling and its role in disease. Blood 2009;114:1289-98.

[18] Kang DH, Kim YG, Andoh TF, Gordon KL, Suga S, Mazzali M, et al. Post-cyclosporine-mediated hypertension and nephropathy: amelioration by vascular endothelial growth factor. Am J Physiol Ren Physiol 2001;280:F727-36.

[19] Hegab AE, Kubo H, Yamaya M, Asada M, He M, Fujino N, et al. Intranasal HGF administration ameliorates the physiologic and morphologic changes in lung emphysema. Mol Ther 2008;16:1417-28.

[20] Ribeiro-Paes JT, Bilaqui A, Greco OT, Ruiz MA, Marcelino MY, Stessuk T, et al. Unicentric study of cell therapy in chronic obstructive pulmonary disease/ pulmonary emphysema. Int J COPD 2011;6:63-71. 
[21] Lüthje L, Raupach T, Michels H, Unsöld B, Hasenfuss G, Kögler H, et al. Exercise intolerance and systemic manifestations of pulmonary emphysema in a mouse model. Respir Res 2009;10:7-17.

[22] Kanellakis P, Slater NJ, Du XJ, Bobik A, Curtis DJ. Granulocyte colonystimulating factor and stem cell factor improve endogenous repair after myocardial infarction. Cardiovasc Res 2006;70:117-25.

[23] Li Y, Takemura G, Okada H, Miyata S, Esaki M, Maruyama R, et al. Treatment with granulocyte colony-stimulating factor ameliorates chronic heart failure. Lab Invest 2006;86:32-44.

[24] Kuhlmann MT, Kirchhof P, Klocke R, Hasib L, Stypmann J, Fabritz L, et al. G$\mathrm{CSF} / \mathrm{SCF}$ reduces inducible arrhythmias in the infarcted heart potentially via increased connexin 43 expression and arteriogenesis. J Exp Med 2006;203: 87-97.

[25] Donnelly LE, Barnes PJ. Chemokine receptors as therapeutic targets in chronic obstructive pulmonary disease. Trends Pharmacol Sci 2006;10:546-53.

[26] Fujita M, Ye Q, Nakashima N, Hamada N, Hagimoto N, Kuwano K, et al. Retinoic acid fails to reverse emphysema in adult mouse models. Thorax 2004;59:224-30.

[27] Stinchcombe SV, Maden M. Retinoic acid-induced alveolar regeneration: critical differences in strain sensitivity. Am J Respir Cell Mol Biol 2008;38: 185-91.

[28] Vlahos R, Bozinovski S, Hamilton JA, Anderson GP. Therapeutic potential of treating chronic obstructive pulmonary disease (COPD) by neutralising granulocyte macrophage-colony stimulating factor (GM-CSF). Pharmacol Ther 2006;112:106-15.
[29] Massaro GD, Massaro D. Retinoic acid treatment abrogates elastase-induced pulmonary emphysema in rats. Nat Med 1997;3:675-7.

[30] Janelle MF, Doucet A, Bouchard D, Bourbonnais Y, Tremblay GM. Increased local levels of granulocyte colony-stimulating factor are associated with the beneficial effect of pre-elafin (SKALP/trappin-2/WAP3) in experimental emphysema. Biol Chem 2006;387:903-9.

[31] Yoshimatsu A, Nan-ya K, Miki I. Effect of nartograstim, a recombinant humam granulocyte colony-stimulating factor on elastase-induced emphysema in rats. Arzneimittelforschung 2009;59:248-53.

[32] Cruz FF, Antunesa MA, Abreu SC, Fujisaki LC, Silva JD, Xisto DG, et al. Protective effects of bone marrow mononuclear cell therapy on lung and heart in an elastase-induced emphysema model. Respir Physiol Neurobiol 2012;182: 26-36.

[33] Mahoney JA, Rosen A. Apoptosis and autoimmunity. Curr Opin Immunol 2005; 17:583-8.

[34] Henson PM, Bratton DL, Fadok VA. Apoptotic cell removal. Curr Biol 2001;11: R795-805.

[35] Fadok VA, Bratton DL, Konowal A, Freed PW, Westcott JY, Henson PM. Macrophages that have ingested apoptotic cells in vitro inhibit proinflammatory cytokine production through autocrine/paracrine mechanisms involving TGF-, PGE2, and PAF. J Clin Invest 1998a;101:890-8.

[36] Fadok VA, Bratton DL, Frasch SC, Warner ML, Henson PM. The role of phosphatidylserine in recognition of apoptotic cells by phagocytes. Cell Death Differ 1998b;5:551-62. 